\section{The Geological Record of Ocean Acidification}

Bärbel Hönisch, ${ }^{1 *}$ Andy Ridgwell, ${ }^{2}$ Daniela N. Schmidt, ${ }^{3}$ Ellen Thomas, ${ }^{4,5}$ Samantha ${ }^{3}$ Gibbs, ${ }^{6}$ Appy Sluijs, ${ }^{7}$ Richard Zeebe, ${ }^{8}$ Lee Kump, ${ }^{9}$ Rowan C. Martindale, ${ }^{10}$ Sarah E. Greene, ${ }^{2,10}$ Wolfgang Kiessling, ${ }^{11}$ Justin Ries, ${ }^{12}$ James C. Zachos, ${ }^{13}$ Dana L. Royer, ${ }^{5}$ Stephen Barker, ${ }^{14}$ Thomas M. Marchitto Jr., ${ }^{15}$ Ryan Moyer, ${ }^{16}$ Carles Pelejero, ${ }^{17}$ Patrizia Ziveri, ${ }^{18,19}$ Gavin L. Foster, ${ }^{6}$ Branwen Williams ${ }^{20}$

Ocean acidification may have severe consequences for marine ecosystems; however, assessing its future impact is difficult because laboratory experiments and field observations are limited by their reduced ecologic complexity and sample period, respectively. In contrast, the geological record contains long-term evidence for a variety of global environmental perturbations, including ocean acidification plus their associated biotic responses. We review events exhibiting evidence for elevated atmospheric $\mathrm{CO}_{2}$, global warming, and ocean acidification over the past $~ 300$ million years of Earth's history, some with contemporaneous extinction or evolutionary turnover among marine calcifiers. Although similarities exist, no past event perfectly parallels future projections in terms of disrupting the balance of ocean carbonate chemistry-a consequence of the unprecedented rapidity of $\mathrm{CO}_{2}$ release currently taking place.

$\mathrm{T}$ he geological record is imprinted with numerous examples of biotic responses to natural perturbations in global carbon cycling and climate change (Fig. 1), some of which could have been caused by large-scale ocean acidification. By reconstructing past changes in marine environmental conditions, we can test hypotheses for the causes and effects of future-

${ }^{1}$ Lamont-Doherty Earth Observatory of Columbia University, Palisades, NY 10964, USA. ² Chool of Geographical Sciences, University of Bristol, Bristol BS8 1SS, UK. ${ }^{3}$ School of Earth Sciences, University of Bristol, Bristol, BS8 1R], UK. ${ }^{4}$ Department of Geology and Geophysics, Yale University, New Haven, CT 06520, USA. ${ }^{5}$ Department of Earth and Environmental Sciences, Wesleyan University, Middletown, CT 06459, USA. ${ }^{6}$ Ocean and Earth Science, National Oceanography Centre Southampton, University of Southampton, Southampton SO14 3ZH, UK. ${ }^{7}$ Department of Earth Sciences, Utrecht University, 3584 CD Utrecht, Netherlands. ${ }^{8}$ School of Ocean and Earth Science and Technology, Department of Oceanography, University of Hawaii at Manoa, Honolulu, HI 96822, USA. ${ }^{\circ}$ Department of Geosciences, Pennsylvania State University, University Park, PA 16802, USA. ${ }^{10}$ Department of Earth Sciences, University of Southern California (USC), Los Angeles, CA 90089 USA. ${ }^{11}$ Museum für Naturkunde at Humboldt University, 10115 Berlin, Germany. ${ }^{12}$ Department of Marine Sciences, University of North Carolina-Chapel Hill, NC 27599, USA. ${ }^{13}$ Earth and Planetary Sciences Department, University of California Santa Cruz, CA 95064, USA. ${ }^{14}$ School of Earth and Ocean Sciences, Cardiff University, Cardiff CF10 3AT, UK. ${ }^{15}$ Department of Geological Sciences and Institute of Arctic and Alpine Research, University of Colorado, Boulder, CO 80309, USA. ${ }^{16}$ University of South Florida St. Petersburg, Department of Environmental Science, Policy, and Geography, St. Petersburg, FL 33701, USA. ${ }^{17}$ Institució Catalana de Recerca i Estudis Avançats and Department of Marine Biology and Oceanography, Consejo Superior de Investigaciones Científicas, 08003 Barcelona, Catalonia, Spain. ${ }^{18}$ Institute of Environmental Science and Technology, Universitat Autònoma de Barcelona, 01893 Barcelona, Spain. ${ }^{19}$ Department of Earth Sciences, Vrije Universiteit, 1081HV Amsterdam, Netherlands. ${ }^{20}$ W. M. Keck Science Department of Claremont McKenna College, Pitzer College, and Scripps College, Claremont, CA 91711, USA.

*To whom correspondence should be addressed. E-mail: hoenisch@ldeo.columbia.edu acidification must be unambiguously identified. In recent years, a variety of trace-element and isotopic tools have become available that can be applied to infer past seawater carbonate chemistry. For instance, the boron isotopic composition $\left(\delta^{11} \mathrm{~B}\right)$ of marine carbonates reflects changes in seawater $\mathrm{pH}$, the trace element (such as $\mathrm{B}, \mathrm{U}$, and $\mathrm{Zn}$ )-to-calcium ratio of benthic and planktic foraminifer shells records ambient $\left[\mathrm{CO}_{3}^{2-}\right]$, and the stable carbon isotopic composition $\left(\delta^{13} \mathrm{C}\right)$ of organic molecules (alkenones) can be used to estimate surface ocean aqueous $\left[\mathrm{CO}_{2}\right](2)$.

Because direct ocean geochemical proxy observations are still relatively scarce, past ocean acidification is often inferred from a decrease in the accumulation and preservation of $\mathrm{CaCO}_{3}$ in marine sediments, potentially indicated by an increased degree of fragmentation of foraminiferal shells (3). However, it is difficult to distinguish between the original calcification responses to chemical changes in the surface ocean and postmortem conditions at the sea floor. For instance, planktic calcifiers may secrete heavier or lighter shells (4), but that signal may be modified at the sea floor through dissolution or overgrowth after deposition $(5,6)$. This duality can introduce controversy over the identification of causes and effects, the drivers of biological change, and

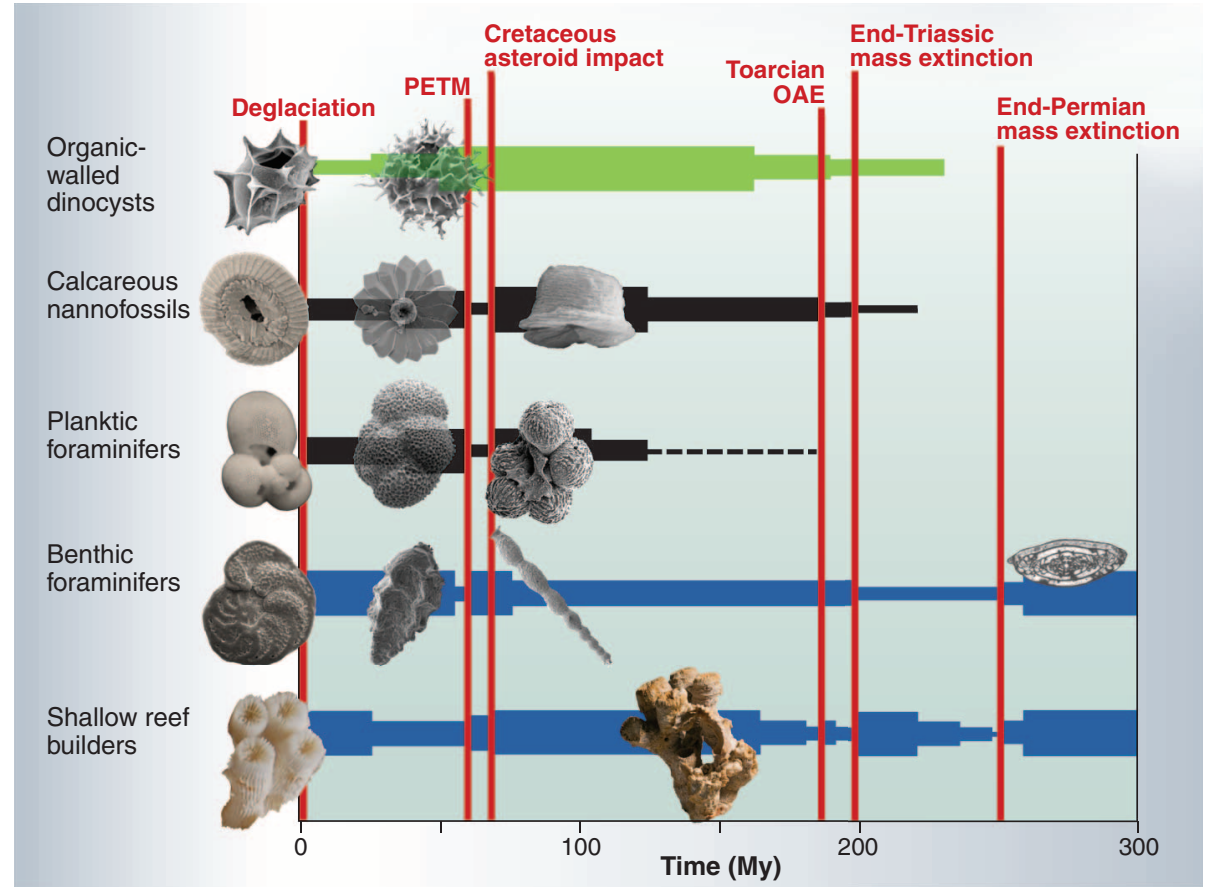

Fig. 1. Idealized diversity trajectories of the calcareous and organic fossil lineages discussed in the text. Extinction and radiation suggest events of major environmental change throughout the past 300 My. Calcareous plankton is shown in black, calcareous benthos in blue, and organic fossils in green, and the line thickness indicates relative and smoothed species richness. Highlighted events (vertical red lines) have been associated with potential ocean acidification events (Fig. 4). Calcareous organisms were not uniformly affected at all times, suggesting the importance of synergistic environmental factors to extinction, adaptation, and evolution as well as different sensitivity due to physiological factors. Identification of a paleo-ocean acidification event therefore requires independent geochemical evidence for ocean chemistry changes. Images of organisms are exemplary. References and further information on the displayed organisms are available in the supporting online material. 


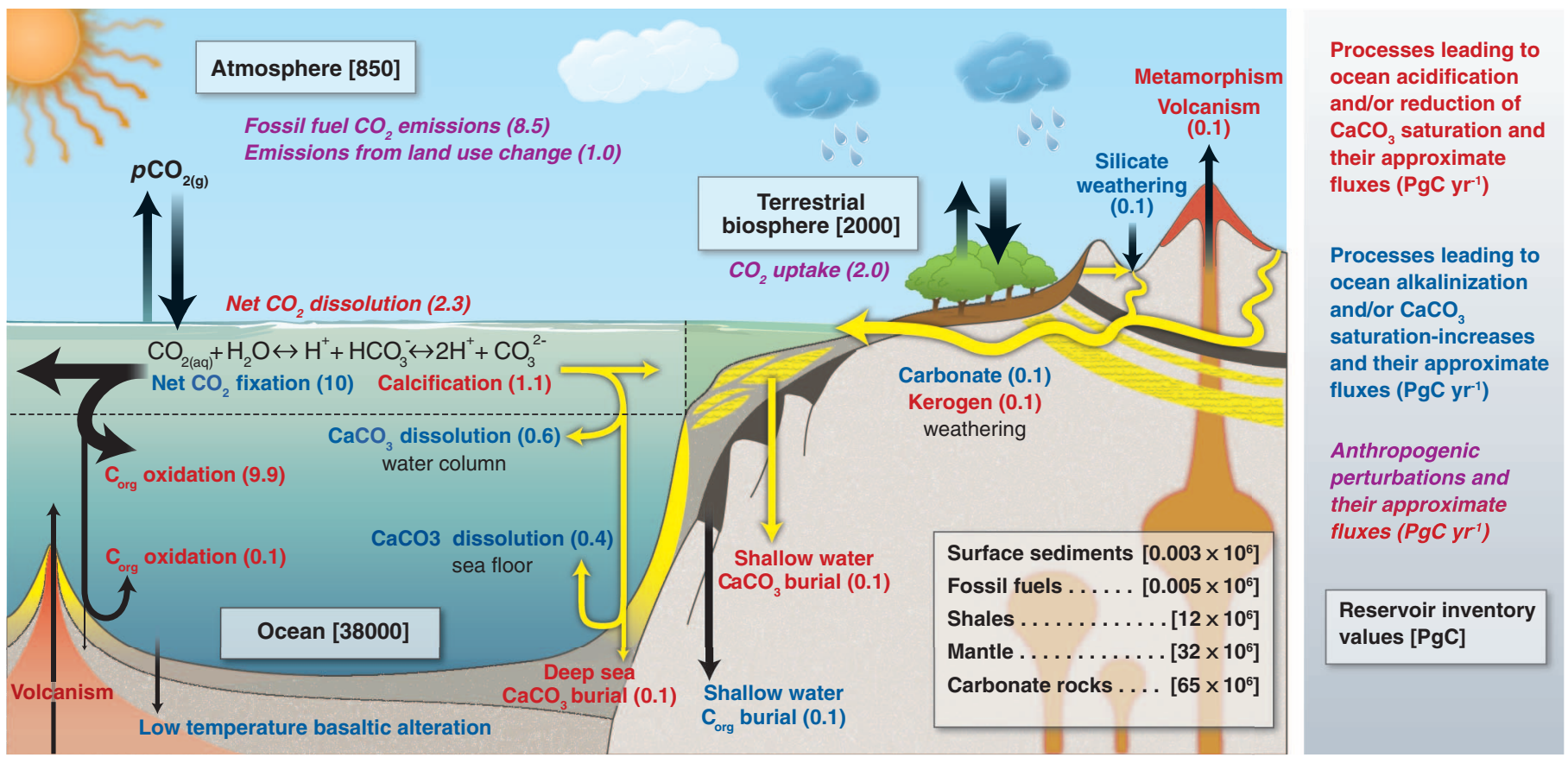

Fig. 2. When $\mathrm{CO}_{2}$ dissolves in seawater, it reacts with water to form carbonic acid, which then dissociates to bicarbonate, carbonate, and hydrogen ions. The higher concentration of hydrogen ions makes seawater acidic, but this process is buffered on long time scales by the interplay of seawater, seafloor carbonate sediments, and weathering on land. Shown are the major pathways of reduced carbon (black) and of alkalinity (yellow). Processes leading to ocean acidification and/or reduction of $\mathrm{CaCO}_{3}$ saturation are indicated in red, and pro- cesses leading to ocean alkalinization and/or $\mathrm{CaCO}_{3}$ saturation increases are indicated in blue. Anthropogenic perturbations are marked in italics. Approximate fluxes are printed in parentheses $\left(\mathrm{PgC}\right.$ year $\left.{ }^{-1}\right)$, whereas reservoir inventory values are shown in brackets $[\mathrm{PgC}]$. Natural carbon cycle fluxes are from (70); anthropogenic fluxes for 2008 are from (57), which for the land sink is significantly above its $1990-2000$ average of $2.6 \mathrm{PgC}_{\text {year }}{ }^{-1}$ due to the 2008 La Niña state (8). whether past intervals of ocean acidification are characterized by environmental conditions relevant for the near future. Coeval changes in ocean circulation will also introduce regional biases in proxy records and hence affect global interpretations.

Here, we review the factors controlling ocean acidification, describe evidence for the occurrence of ocean acidification events in the past, and discuss the potential as well as weaknesses of the geological record in helping us predict future ecosystem changes.

\section{Is Ocean Acidification Primarily a pH-Decline Phenomenon?}

The current rate of anthropogenic $\mathrm{CO}_{2}$ release leads to a surface ocean environment characterized not only by elevated dissolved $\mathrm{CO}_{2}$ and decreased $\mathrm{pH}$ (7) but, critically, decreased saturation with respect to calcium carbonate $\left(\mathrm{CaCO}_{3}\right)$, a compound widely used by marine organisms for the construction of their shells and skeletons (8). In contrast, slower rates of $\mathrm{CO}_{2}$ release lead to a different balance of carbonate chemistry changes and a smaller seawater $\mathrm{CaCO}_{3}$ saturation response, which may induce differential biotic response or even no response at all, invalidating a direct analog. The reason for a smaller saturation response to slow $\mathrm{CO}_{2}$ release is that the alkalinity released by rock weathering on land must ultimately be balanced by the preservation and burial of $\mathrm{CaCO}_{3}$ in marine sediments (Fig. 2), which itself is controlled by the calcium carbonate saturation state of the ocean (9). Hence, $\mathrm{CaCO}_{3}$ saturation is ultimately regulated primarily by weathering on long time scales, not atmospheric partial pressure of $\mathrm{CO}_{2}\left(\mathrm{PCO}_{2}\right)$. While weathering itself is related to atmospheric $P_{\mathrm{CO}_{2}}(10)$, it is related much more weakly than ocean $\mathrm{pH}$, which allows $\mathrm{pH}$ and $\mathrm{CaCO}_{3}$ saturation to be almost completely decoupled for slowly increasing atmospheric $\mathrm{PCO}_{2}$.

Using a global carbon cycle model (2), we show the progressive coupling between $\mathrm{CaCO}_{3}$ saturation and $\mathrm{pH}$ as the rate of $\mathrm{CO}_{2}$ emissions increases and sources (weathering) and sinks $\left(\mathrm{CaCO}_{3}\right.$ burial) of alkalinity are no longer balanced. For rapid century-scale and thus futurerelevant increases in atmospheric $P_{\mathrm{CO}_{2}}$, both surface ocean $\mathrm{pH}$ and saturation state decline in tandem (Fig. 3). The projected decrease in ocean surface saturation state-here, with respect to aragonite $\left(\Omega_{\text {aragonite }}\right)$ - is an order of magnitude larger for a rapid $\mathrm{CO}_{2}$ increase than for a slow [100 thousand years (ky)] $\mathrm{CO}_{2}$ increase. Ultimately, saturation recovers while the $\mathrm{pH}$ remains suppressed, reflecting how changes in the oceanic concentrations of dissolved inorganic carbon (DIC) and alkalinity make it possible to have simultaneously both high $\mathrm{CO}_{2}$ and high carbonate ion concentration saturation $\left(\left[\mathrm{CO}_{3}^{2-}\right]\right.$, which controls saturation), but with the relatively greater increase in $\left[\mathrm{CO}_{2}\right]$ causing lower $\mathrm{pH}$. The key to unlocking the geological record of ocean acid- ification is hence to distinguish between longterm steady states and transient changes. We use the term "ocean acidification event" for time intervals in Earth's history that involve both a reduction in ocean $\mathrm{pH}$ and a substantial lowering of $\mathrm{CaCO}_{3}$ saturation, implying a time scale on the order of 10,000 years and shorter (Fig. 3).

\section{Indications of Paleo-Ocean Acidification}

With these criteria in mind, we review (in reverse chronological order) the intervals in Earth's history for which ocean acidification has been hypothesized, along with the evidence for independent geochemical and biotic changes. We confine this review to the past $\sim 300$ million years (My) because the earlier Phanerozoic (and beyond) lacks the pelagic calcifiers that not only provide key proxy information but also create the strong deepsea carbonate (and hence atmospheric $\mathrm{PCO}_{2}$ ) buffer that characterizes the modern Earth system (9). Our criteria for identifying potentially futurerelevant past ocean acidification are (i) massive $\mathrm{CO}_{2}$ release, (ii) $\mathrm{pH}$ decline, and (iii) saturation decline. We also discuss evidence for the time scale of $\mathrm{CO}_{2}$ release, as well as for global warming. Events are given a similarity index that is based on available geochemical data (table S1) and are indicated in Fig. 4A.

Late Pleistocene deglacial transitions. The last deglaciation is the best documented past event associated with a substantive $(30 \%) \mathrm{CO}_{2}$ rise: 189 to $265 \mu \mathrm{atm}$ between 17.8 to 11.6 ky before 
the present (B.P.) (11). Boron isotope estimates from planktic foraminifers show a $0.15 \pm 0.05$ unit decrease in sea surface $\mathrm{pH}$ (12) across the deglacial transition - an average rate of decline of $\sim 0.002$ units per 100 years compared with the current rate of more than 0.1 units per 100 years (table S1). Planktic foraminiferal shell weights decreased by 40 to $50 \%$ (4), and coccolith mass decreased by $\sim 25 \%$ (13). In the deep ocean, changes in carbonate preservation (14), $\mathrm{pH}$ [from foraminiferal $\left.\delta^{11} \mathrm{~B}(15)\right]$ and $\left[\mathrm{CO}_{3}^{2-}\right.$ ] [from foraminiferal $\mathrm{B} / \mathrm{Ca}$ and $\mathrm{Zn} / \mathrm{Ca}$ $(16,17)]$ differed between ocean basins, reflecting covarying changes in deep-water circulation and an internal carbon shift within the ocean. The regional nature of these variations highlights the general need for careful evaluation of regional versus global effects in paleo-studies.

Oligocene-Pliocene. The climate of the Oligocene to Pliocene [34 to 2.6 million years ago (Ma)] contains intervals of elevated temperature and modest deviations of atmospheric $\mathrm{PCO}_{2}$ from modern values (Fig. 4). Of particular interest has been the Pliocene warm period [3.29 to $2.97 \mathrm{Ma}(18,19)]$, which is characterized by global surface temperatures estimated to be $\sim 2.5^{\circ} \mathrm{C}$ higher than today (19), atmospheric $\mathrm{PCO}_{2}$ between 330 to $400 \mu \mathrm{atm}$ (Fig. 4C) $(18,20)$, and sea surface $\mathrm{pH}_{(\mathrm{T})} \sim 0.06$ to 0.11 units lower (18) than the preindustrial. Ecological responses to the warming include migration of tropical foraminifer species toward the poles (21), but there are no documented calcification responses or increased nannoplankton extinction rates (22). The early to middle Miocene (23 to $11 \mathrm{Ma}$ ) and Oligocene (34 to $23 \mathrm{Ma}$ ) were also characterized periods of elevated temperatures and slightly higher $\mathrm{PCO}_{2}$ compared with preindustrial values (Fig. 4C) but, because of their long duration, were not associated with changes in $\mathrm{CaCO}_{3}$ saturation (Fig. 3C).

Paleocene-Eocene. Evidence for rapid carbon injection associated with the Paleocene-Eocene Thermal Maximum (PETM, 56 $\mathrm{Ma}$ ) as well as a number of smaller transient global warming events (hyperthermals) during the late Paleocene and early Eocene (58 to $51 \mathrm{Ma}$ ) comes primarily from observations of large [up to -4 per mil (\%o)] negative $\delta^{13} \mathrm{C}$ excursions (23) associated with pronounced decreases in calcium carbonate preservation (24). Depending on the assumed source, rate, and magnitude of $\mathrm{CO}_{2}$ release (25), a 0.25 to 0.45 unit decline in surface seawater $\mathrm{pH}$ is possible, with a reduction in mean surface ocean aragonite saturation from $\Omega=3$ down to 1.5 to 2 (1). The calcite compensation depth (CCD) (8) rose by $\sim 2 \mathrm{~km}$ to shallower than
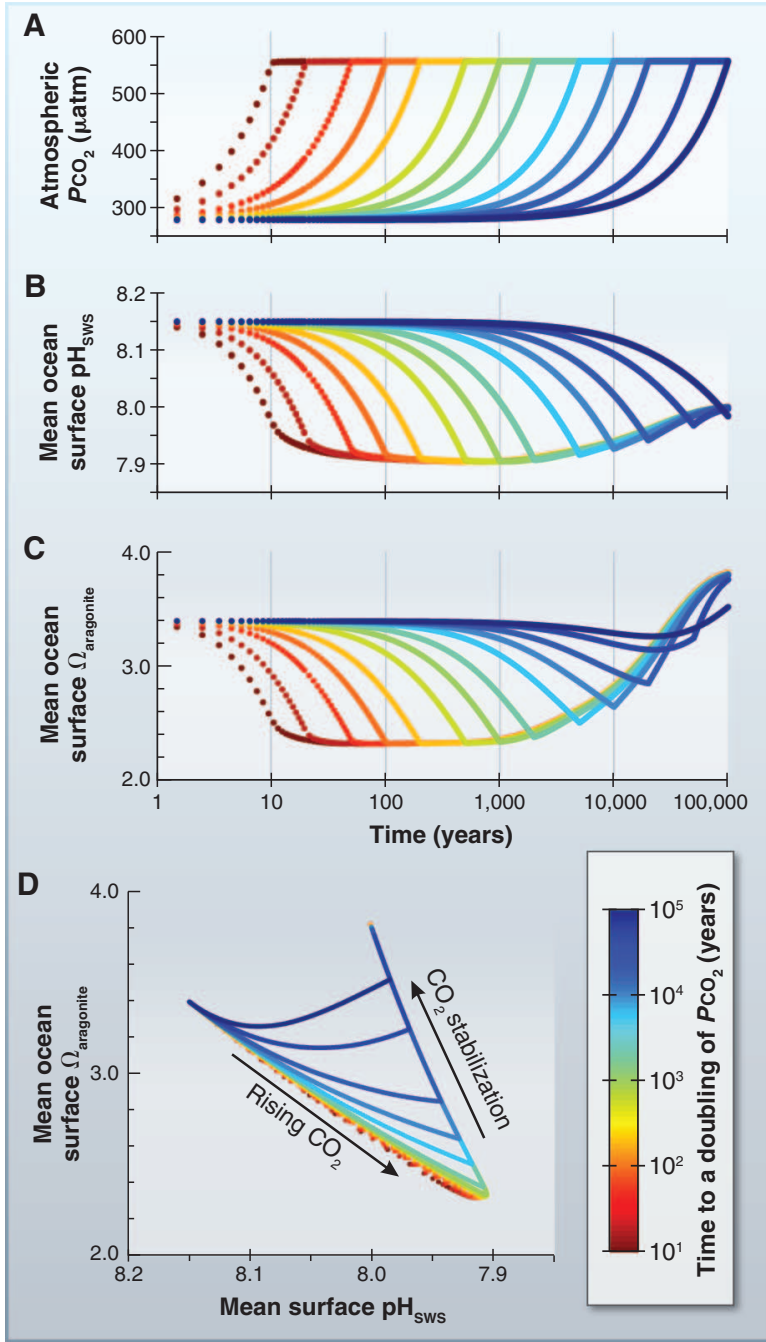

Fig. 3. The trajectories of mean ocean surface $\mathrm{pH}$ and aragonite saturation ( $\Omega_{\text {aragonite }}$ ) become progressively decoupled as the rate of atmospheric $P_{\mathrm{CO}_{2}}$ change increases. The four panels show the results of a series of experiments in an Earth system model (2). (A) Prescribed linear increases of atmospheric $P \mathrm{CO}_{2}$ (on a $\log _{10}$ scale) from $\times 1$ to $\times 2$ preindustrial $\mathrm{CO}_{2}$, with the different model experiments spanning a range of time scales (but experiencing the same ultimate $\mathrm{CO}_{2}$ change). (B) Evolution of mean surface $\mathrm{pH}$ in response to rising $\mathrm{CO}_{2}$. (C) Evolution of mean surface $\Omega_{\text {aragonite }}$ (D) A cross-plot illustrating how $\Omega_{\text {aragonite }}$ is progressively decoupled from pH as the rate of $\mathrm{PCO}_{2}$ increase slows, with future-relevant rate of $\mathrm{PCO}_{2}$ increase showing a diagonal trajectory from top left to bottom right, whereas slow $\mathrm{PCO}_{2}$ increases result in an almost horizontal trajectory toward lower $\mathrm{pH}$ with very little saturation change. All plots are color-coded from red ("fast") to blue ("slow"). These model results include both climate and long-term (silicate) weathering feedback. See (2) and fig. S1 for the role of these and other feedbacks.
$1.5 \mathrm{~km}$ in places (24) (compared with $>4 \mathrm{~km}$ today). Although a $\mathrm{pH}$ decrease or $\mathrm{PCO}_{2}$ increase remains to be confirmed by geochemical proxies for any of the hyperthermal events, the amount of carbon injected can be modeled on the basis of consistent carbonate $\delta^{13} \mathrm{C}$ and CCD changes, yielding between $\sim 2000$ and $6000 \mathrm{PgC}$ for the onset of the PETM $(26,27)$. However, as with the last glacial transition, deep sea geochemistry appears strongly modulated by regional ocean circulation changes (28), which adds an additional layer of complexity to global extrapolation and highlights the importance of adequate spatial coverage of the data.

PETM sediments record the largest extinction among deep-sea benthic foraminifers of the past $75 \mathrm{My}$ (29), and a major change in trace fossils indicates a disruption of the macrobenthic community (30). However, the covariation of ocean acidification, warming, and corresponding oxygen depletion (fig. S2) (23) precludes the attribution of this extinction to a single cause $(1,29)$. In shallow water environments, a gradual shift from calcareous red algae and corals to larger benthic foraminifers as dominant calcifiers started in the Paleocene and was completed at the PETM with the collapse of coralgal reefs and larger benthic foraminiferal turnover (31). This event is recognized as one of the four major metazoan reef crises of the past 300 My (Fig. 1) (32). In marginal marine settings, coccolithophore (33) and dinoflagellate cyst (34) assemblages display changes in species composition, but these are interpreted to reflect sensitivity to temperature, salinity stratification, and/or nutrient availability $(34,35)$, not necessarily acidification (fig. S2). In the open ocean, the occurrence of deformities in some species of calcareous nannoplankton has been described (36), but despite a strong change in assemblages, there is no bias in extinction or diversification in favor of or against less or more calcified planktic species (37).

Cretaceous and Cretaceous-Paleogene. The well-known mass extinction at $65 \mathrm{Ma}$ is generally accepted to have been triggered by a large asteroid impact (38). In addition to potential terrestrial biomass or fossil carbon burning, the impact may have caused the emission of $\mathrm{SO}_{2}$ from vaporized gypsum deposits at the impact site and/or nitric acid aerosols produced by shock heating of the atmosphere, which could have led to acid rain and hence potentially to rapid acidification of the surface ocean (38). Although planktic calcifiers exhibited elevated rates of extinction and reduced production $(22,39)$, reef corals did not experience a major extinction (32), and benthic foraminifers were not affected in either shallow or deep waters (29). Because multiple environmental changes covaried and proxy data for marine carbonate chemistry are not yet available, unambiguous attribution of the planktic extinctions to any one driver such as ocean acidification is currently not possible.

The earlier Cretaceous (K) (Fig. 4A) is generally a time of massive chalk deposition (mainly 
in the form of nannofossil calcite), as well as one of elevated $\mathrm{PCO}_{2}$ (Fig. 4B) and lower pH (Fig. 4D). This association can be misconceived as evidence that marine calcification will not be impaired under conditions of low $\mathrm{pH}$ in the future. However, this reasoning is invalid because extended periods of high $\mathrm{PCO}_{2}$ (Fig. 4B) do not necessarily result in a suppressed seawater calcite saturation state (Fig. 3) $(1,40)$, which exerts an important control on organisms' calcification (41).

Cretaceous and Jurassic oceanic anoxic events. The Mesozoic oceanic anoxic events (OAEs) (in particular, OAE $2 \sim 93 \mathrm{Ma}$, OAEla $\sim 120 \mathrm{Ma}$, and Toarcian OAE $\sim 183$ Ma) were intervals during which the ocean's oxygen minimum and deep anoxic zones expanded markedly (42). The onsets of these OAEs have been linked to the emplacement of large igneous provinces, degassing large amounts of $\mathrm{CO}_{2}$ and associated environmental consequences of warming, lower oxygen solubility, and possibly ocean acidification (42). Some of the Cretaceous OAEs were associated with turnover in plankton communities (43). Deformities and some minor size reduction in coccoliths, as well as a massive increase in the abundance of heavily calcified nannoconids, have been observed $(44,45)$. However, similar to more recent events, there is difficulty in unequivocally attributing observations to surface water acidification given the covariation of environmental changes (46).

Because most old sea floor ( $\sim 180 \mathrm{Ma}$ or older) is subducted, the sedimentary record of the Toarcian OAE is now restricted to former continental margins. Sedimentary organic and inorganic carbon deposits display initially negative, followed by positive $\delta^{13} \mathrm{C}$ excursions, which is consistent with an influx of $\mathrm{CO}_{2}$ into the atmosphere followed by organic carbon burial (42). The negative isotopic transition occurs in distinct negative $\delta^{13} \mathrm{C}$ shifts, each estimated to occur in less than $20 \mathrm{ky}(47)$ and possibly in as little as 650 years (48). The Toarcian OAE is associated with a reef crisis that was particularly selective against corals and hypercalcifying sponges (animals with a large skeletal-toorganic biomass ratio) (Fig. 4B) (32) and with a decrease in nannoplankton flux (49). Again, these observations could have been a response to any one or combination of a number of different contemporaneous environmental changes.

\begin{tabular}{lcc}
\multicolumn{3}{c}{ Phanerozoic } \\
\hline Cenozoic & Mesozoic & Paleozoic
\end{tabular}
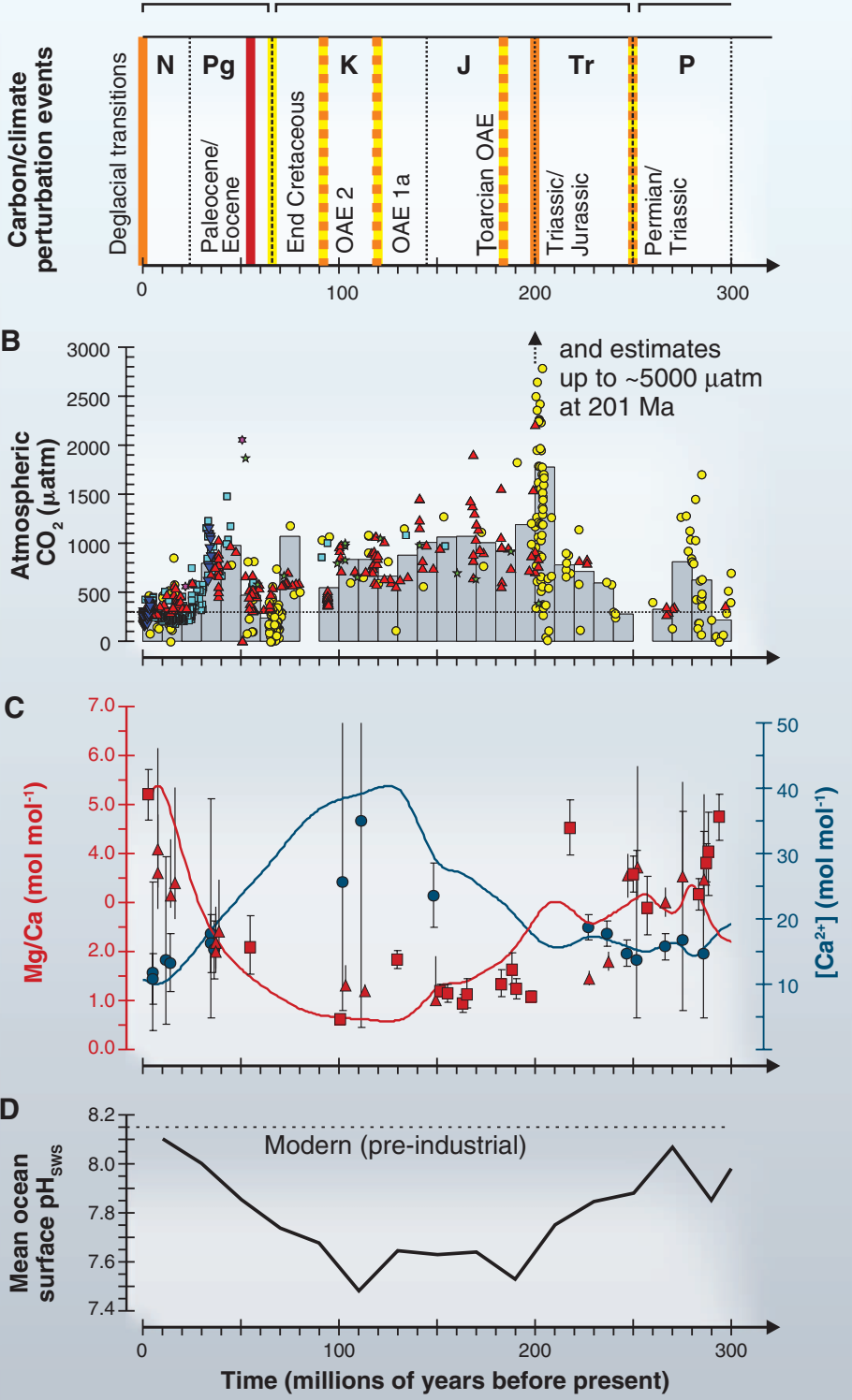

Fig. 4. Compilation of data-based [(B) and (C)] and model-reconstructed $[(C)$ and $(D)]$ indicators of global carbon cycle evolution over the past 300 My together with candidate ocean acidification events $(A)$. (A) Summarization of the degree to which events (table S1) have some similarity to modern ocean acidification. The similarity index (table S1) is color-coded, where red indicates $3 /$ most similar, orange indicates 2/partly similar, and yellow indicates 1/unlike. (B) Proxy-reconstructed atmospheric $\mathrm{PCO}_{2}$ (2) grouped by proxy: yellow circles indicate paleosol $\delta^{13} \mathrm{C}$, light blue squares indicate marine phytoplankton $\delta^{13} \mathrm{C}$, red triangles indicate stomatal indices/ ratios, dark blue inverted triangles indicate planktic foraminiferal $\delta^{11} \mathrm{~B}$, green five-pointed stars indicate liverwort $\delta^{13} \mathrm{C}$, purple six-pointed stars indicate sodium carbonates, with 10-My averages shown by gray bars. For plotting convenience, estimates exceeding $3000 \mu \mathrm{atm}$ are not shown [primarily paleosol $\delta^{13} \mathrm{C}$ from the uppermost Triassic/lowermost Jurassic (2)]. (C) Ocean Mg/Ca ratios (red triangles, left axis), reconstructed from fluid inclusions (2) and echinoderm fossil carbonate [red squares (71)] together with the Phanerozoic seawater model of (72) (red line). Also shown (blue circles, right axis) is $\left[\mathrm{Ca}^{2+}\right]$ from fluid inclusions (2) and models [blue line (72)]. (D) Model-reconstructed changes in mean ocean surface $\mathrm{pH}$ at 20-My intervals [black line (73)].
Triassic-Jurassic. The Triassic-Jurassic (T/J) mass extinction is linked to the coeval emplacement of the Central Atlantic Magmatic Province (50). Proxy records across the $\mathrm{T} / \mathrm{J}$ boundary $(\sim 200 \mathrm{Ma})$ suggest a doubling of atmospheric $\mathrm{PCO}_{2}$ over as little as $20 \mathrm{ky}(51,52)$, although the absolute $\mathrm{PCO}_{2}$ estimates differ greatly between proxies, with leaf stomata suggesting an increase from 700 to $2000 \mu \mathrm{atm}$, whereas pedogenic carbonates indicate an increase from 2000 to 4400 $\mu \mathrm{atm}$ (Fig. 4C) (2). Decreased carbonate saturation is inferred from reduced pelagic carbonate accumulation in shelf sediments (53), although shallow water carbonate deposition can vary in response to many parameters, not only acidification. A calcification crisis amongst hypercalcifying taxa is inferred for this period (Fig. 4B), with reefs and scleractinian corals experiencing a near- total collapse (32). However, the observation that tropical species were more affected than extratropical species suggests that global warming may have been an important contributor or even dominant cause of this extinction (32).

Permian-Triassic. The Permo-Triassic $(\mathrm{P} / \mathrm{T})$ mass extinction (252.3 Ma) was the most severe of the Phanerozoic Era and coincided, at least in part, with one of the largest known continental eruptions, the Siberian trap basalts. Recent estimates for the total $\mathrm{CO}_{2}$ release put it at $\sim 13,000$ to $43,000 \mathrm{PgC}$ in 20 to $400 \mathrm{ky}(54-56)$ - an annual carbon release of $\sim 0.1$ to $1 \mathrm{PgC}$ [compared with $9.9 \mathrm{PgC}$ in 2008 (57)]. There is some observational evidence for carbonate dissolution in shelf settings (54), but its interpretation is again debated (58). There is abundant evidence for ocean anoxia, photic zone euxinia (enrichment in 
hydrogen sulfide) (59), and strong warming (54), but no direct proxy evidence for $\mathrm{pH}$ or carbonate ion changes. Knoll et al. (59) inferred the preferential survival of taxa with anatomical and physiological features that should confer resilience to reduced carbonate saturation state and hypercapnia (high $\mathrm{CO}_{2}$ in blood) and preferential extinction of taxa that lacked these traits, such as reef builders (32).

\section{Is There a Geologic Analog for the Future?}

A number of past ocean carbon-cycle perturbation events share many of the characteristics of anthropogenic ocean acidification (Fig. 4 and table $\mathrm{S} 1$ ), with the notable exception of the estimated rates of $\mathrm{CO}_{2}$ release. In the general absence of direct proxy evidence for lower $\mathrm{pH}$ and reduced saturation before the Pliocene, global carbon cycle models can be used to infer the magnitude of carbon release by fitting observed changes in the $\delta^{13} \mathrm{C}$ of calcium carbonates and organic remnants (60). However, as well as needing information on the source and isotopic composition of the added carbon, the time scale of $\delta^{13} \mathrm{C}$ change is critically important to the estimation of $\mathrm{CO}_{2}$ fluxes (25). Because of the lack of open-ocean sediments and increasingly poor temporal and spatial resolution of the geological record further back in time, it is difficult to place adequate constraints on the duration and rate of $\mathrm{CO}_{2}$ release. Radiometric dating techniques are not accurate enough to identify Mesozoic intervals of 10-ky duration, although orbital spectral analysis of highly resolved isotope and/or sedimentological records can help to partly overcome this - for example, if a $\delta^{13} \mathrm{C}$ excursion is shorter or longer than one precession cycle [21 ky (51)]. Even for the wellstudied PETM, the duration of the main phase of this carbon injection is still debated $(35,61)$, and model-inferred peak rates of $\leq 1 \mathrm{PgC}$ per year $(26,61)$ could potentially be an underestimate.

Additional complications arise because carbon may not have been released at a uniform rate and, in the extreme, may have occurred in the form of rapid pulses. In such cases, the assumption of an average emissions rate throughout the entire duration of the pulsed release will fail to capture the potential for episodes of intense acidification. For instance, although the total duration of the $\mathrm{CO}_{2}$ release from the $\mathrm{T} / \mathrm{J}$-age Central Atlantic Magmatic Province was estimated to be $\sim 600 \mathrm{ky}$, pulses as short as $\sim 20 \mathrm{ky}$ have been suggested $(51,62)$. Similarly, the main phase of OAE1a (excluding the recovery interval) was $\sim 150 \mathrm{ky} \mathrm{(45)}$ and hence too slow for carbonate saturation to be significantly affected (Fig. 3), but major volcanic eruptions and thus rapid $\mathrm{CO}_{2}$ release could potentially have produced future-relevant perturbations in the carbon cycle. Substantially improved chronologies and higherresolution records are needed to refine estimates of rate.

Given current knowledge of the past $300 \mathrm{My}$ of Earth's history (Fig. 4 and table S1), the PETM and associated hyperthermal events, the $\mathrm{T} / \mathrm{J}$, and potentially the $\mathrm{P} / \mathrm{T}$ all stand out as having excellent potential as analog events, although the $T / \mathrm{J}$ and $\mathrm{P} / \mathrm{T}$ are much more poorly constrained because of the absence of deep-sea carbonate deposits. OAEs may also be relevant but were associated with less severe volcanism $\left(\mathrm{CO}_{2}\right.$ release) than were the older events $(\mathrm{P} / \mathrm{T}$ and $\mathrm{T} / \mathrm{J})$. The last deglacial transition, although characterized by temperature and $\mathrm{CO}_{2}$-increase, is two orders of magnitude slower than current anthropogenic change. It is also thought to largely represent a redistribution of carbon within the ocean and to the atmosphere and terrestrial biosphere and hence did not have as potent and globally uniform an acidification effect as an input from geological reserves. Because of the decoupling between $\mathrm{pH}$ and saturation on long time scales (Fig. 3), extended intervals of elevated $\mathrm{PCO}_{2}$ such as the middle Miocene, Oligocene, and Cretaceous can be firmly ruled out as future-relevant analogs.

\section{What Are the Perspectives for Using the Geological Record to Project Global Change?}

Only rapid or pulsed $\mathrm{CO}_{2}$ release events can provide direct future-relevant information. Assessment of such events critically depends on independent geochemical quantification of the associated changes in the carbonate system, specifically seawater-pH and $\mathrm{CaCO}_{3}$ saturation. Geochemical proxy estimates are not yet available for the Cretaceous and beyond and need to be obtained to verify whether ocean acidification did indeed happen. This is challenging, because in addition to the potential for increasing postdepositional alteration and reduced stratigraphic exposure, uncertainty over the chemical and isotopic composition of seawater increases and limits our interpretation of these proxies $(63,64)$. Future studies will have to improve and expand geochemical estimates and their uncertainties of surface and deep-ocean carbonate chemistry associated with carbonate dissolution and ecological changes. This includes finding new archives to study the secular evolution of seawater chemistry but also the laboratory study of living proxy carriers under conditions mimicking past seawater chemistry. An unfortunate aspect of the geological record, however, is the lack of deep-sea carbonates in the Early Jurassic and beyond, which further reduces our ability to reconstruct the carbonate chemistry of those older events.

The sensitivity of ocean chemistry to $\mathrm{CO}_{2}$ release, and the relationship between induced $\mathrm{pH}$ and $\mathrm{PCO}_{2}$ changes, vary through time and further complicate the picture. For instance, seawater calcium and magnesium ion concentrations were different in the past (Fig. 4C). This alters the ocean's carbonate ion buffering capacity and hence sensitivity of the Earth system to carbon perturbation (65) because all other things being equal, higher ambient $\mathrm{Ca}^{2+}$ concentrations means that a lower carbonate ion concentration is required to achieve the same saturation and hence balance weathering. Varying seawater $\mathrm{Mg} / \mathrm{Ca}$ ratios may potentially also affect the mineralogy of marine calcifiers, where the more soluble high-Mg calcite predominated Neogene reefs and reefs during the Permian through Early Jurassic, and more resistant low-Mg calcite predominated during the Late Jurassic through Paleogene (66). Thus, on this mineralogical basis the response of marine calcifiers to ocean acidification and seawater geochemistry during the $\mathrm{P} / \mathrm{T}$ and $\mathrm{T} / \mathrm{J}$ would arguably be closer to the modern than, for example, during the PETM (67). Improved estimates of past seawater- $\mathrm{Mg} / \mathrm{Ca}$ composition are necessary to better evaluate all of this.

Although we have concentrated on the prospects for extracting information from the geological record concerning the impact of ocean acidification, we must question whether it really is necessary to isolate its effect on marine organisms from other covarying factors (68). In particular, consequences of increasing atmospheric $\mathrm{CO}_{2}$ will also be associated with warming in the surface ocean and a decrease in dissolved oxygen concentration (69). Massive carbon release, whether future or past, will hence share the same combination and sign of environmental changes. The strength of the geological record therefore lies in revealing past coupled warming and ocean acidification (and deoxygenation) events as an "integrated" analog, with future and past events sharing the same combination and sign of environmental changes. However, in additionally driving a strong decline in calcium carbonate saturation alongside $\mathrm{pH}$, the current rate of (mainly fossil fuel) $\mathrm{CO}_{2}$ release stands out as capable of driving a combination and magnitude of ocean geochemical changes potentially unparalleled in at least the last $~ 300$ My of Earth history, raising the possibility that we are entering an unknown territory of marine ecosystem change.

\section{References and Notes}

1. A. Ridgwell, D. N. Schmidt, Nat. Geosci. 3, 196 (2010).

2. Materials and methods are available as supporting material on Science Online.

3. W. H. Berger, Deep-Sea Res. 15, 31 (1968).

4. S. Barker, H. Elderfield, Science 297, 833 (2002).

5. S. Barker et al., Paleoceanography 19, PA3008 (2004).

6. S. J. Gibbs, H. M. Stoll, P. R. Bown, T. J. Bralower, Earth Planet. Sci. Lett. 295, 583 (2010).

7. K. Caldeira, M. E. Wickett, Nature 425, 365 (2003)

8. An online associated carbonate chemistry tutorial is available as supporting material on Science Online.

9. A. Ridgwell, R. E. Zeebe, Earth Planet. Sci. Lett. 234, 299 (2005).

10. D. Archer, H. Kheshgi, E. Maier-Reimer, Geophys. Res. Lett. 24, 405 (1997).

11. E. Monnin et al., Science 291, 112 (2001)

12. B. Hönisch, N. G. Hemming, Earth Planet. Sci. Lett. 236 , 305 (2005)

13. L. Beaufort et al., Nature 476, 80 (2011).

14. J. W. Farrell, W. Prell, Paleoceanography 4, 447 (1989).

15. B. Hönisch, T. Bickert, N. G. Hemming, Earth Planet Sci. Lett. 272, 309 (2008).

16. J. Yu et al., Science 330, 1084 (2010).

17. T. M. Marchitto, J. Lynch-Stieglitz, S. R. Hemming, Earth Planet. Sci. Lett. 231, 317 (2005).

18. O. Seki et al., Earth Planet. Sci. Lett. 292, 201 (2010).

19. A. M. Haywood et al., Global Planet. Change 66, 208 (2009)

20. M. Pagani, Z. Liu, ]. LaRiviere, A. C. Ravelo, Nat. Geosci. 3, 27 (2010) 
21. H. ]. Dowsett, M. M. Robinson, Micropaleontology 53 , 105 (2007).

22. P. R. Bown et al., in Coccolithophores-From Molecular Processes to Global Impacts, H. R. Thierstein, ]. R. Young, Eds. (Springer, Berlin, 2004), pp. 481-508.

23. J. P. Kennett, L. D. Stott, Nature 353, 225 (1991).

24. J. C. Zachos et al., Science 308, 1611 (2005).

25. J. C. Zachos, H. McCarren, B. Murphy, U. Röhl, T. Westerhold, Earth Planet. Sci. Lett. 299, 242 (2010).

26. R. E. Zeebe, J. C. Zachos, G. R. Dickens, Nat. Geosci. 2, 576 (2009).

27. K. Panchuk, A. Ridgwell, L. R. Kump, Geology 36 315 (2008).

28. R. E. Zeebe, J. C. Zachos, Paleoceanography 22, PA3201 (2007).

29. E. Thomas, in Geological Society of America Special Paper, S. Monechi, R. Coccioni, M. R. Rampino, Eds. (Geological Society of America, Boulder, CO, 2007) pp. 1-23.

30. F. ]. Rodríguez-Tovar, A. Uchman, L. Alegret, E. Molina, Mar. Geol. 282, 178 (2011).

31. C. Scheibner, R. P. Speijer, Earth Sci. Rev. 90, 71 (2008).

32. W. Kiessling, C. Simpson, Glob. Change Biol. 17, 56 (2011).

33. S. J. Gibbs, T. J. Bralower, P. R. Bown, J. C. Zachos, L. M. Bybell, Geology 34, 233 (2006)

34. A. Sluijs, H. Brinkhuis, Biogeosciences 6, 1755 (2009).

35. A. Sluijs et al., Nat. Geosci. 2, 777 (2009).

36. I. Raffi, B. De Bernardi, Mar. Micropaleontol. 69, 119 (2008).

37. S. J. Gibbs, P. R. Bown, J. A. Sessa, T. J. Bralower, P. A. Wilson, Science 314, 1770 (2006).

38. P. Schulte et al., Science 327, 1214 (2010).

39. S. D'Hondt, M. E. Q. Pilson, H. Sigurdsson, A. K. Hanson Jr., S. Carey, Geology 22, 983 (1994).

40. R. E. Zeebe, P. Westbroek, Geochem. Geophys. Geosyst. 4, 1104 (2003).

41. C. Langdon et al., Global Biogeochem. Cycles 14, 639 (2000).
42. H. C. Jenkyns, Geochem. Geophys. Geosyst. 11, Q03004 (2010).

43. R. M. Leckie et al., Paleoceanography 17, 1041 (2002).

44. E. Erba, F. Tremolada, Paleoceanography 19, PA1008 (2004).

45. E. Erba, C. Bottini, H. J. Weissert, C. E. Keller, Science 329, 428 (2010).

46. S. ]. Gibbs, S. A. Robinson, P. R. Bown, T. D. Jones, J. Henderiks, Science 332, 175; author reply, 175 (2011).

47. G. Suan et al., Earth Planet. Sci. Lett. 267, 666 (2008).

48. A. S. Cohen, A. L. Coe, D. B. Kemp, J. Geol. Soc. London 164, 1093 (2007).

49. E. Mattioli, B. Pittet, L. Petitpierre, S. Mailliot, Global Planet. Change 65, 134 (2009).

50. J. H. Whiteside, P. E. Olsen, D. V. Kent, S. J. Fowell, M. Et-Touhami, Palaeogeogr. Palaeoclimatol. Palaeoecol. 244, 345 (2007).

51. D. B. Kemp, A. L. Coe, A. S. Cohen, L. Schwark, Nature 437, 396 (2005).

52. M. Ruhl, N. R. Bonis, G. ]. Reichart, ]. S. Sinninghe Damsté, W. M. Kürschner, Science 333, 430 (2011).

53. A. E. Crne, H. Weissert, S. Gorican, S. M. Bernasconi, Geol. Soc. Am. Bull. 123, 40 (2011).

54. J. L. Payne et al., Proc. Natl. Acad. Sci. U.S.A. 107, 8543 (2010).

55. S. V. Sobolev et al., Nature 477, 312 (2011).

56. S. Z. Shen et al., Science 334, 1367 (2011).

57. C. Le Quéré et al., Nat. Geosci. 2, 831 (2009).

58. P. B. Wignall, S. Kershaw, P.-Y. Collin, S. Crasquin-Soleau, Geol. Soc. Am. Bull. 121, 954 (2009).

59. A. H. Knoll, R. K. Bambach, ]. L. Payne, S. Pruss, W. W. Fischer, Earth Planet. Sci. Lett. 256, 295 (2007).

60. J. Zachos, M. Pagani, L. Sloan, E. Thomas, K. Billups, Science 292, 686 (2001)

61. Y. Cui et al., Nat. Geosci. 4, 481 (2011).

62. M. Ruhl et al., Earth Planet. Sci. Lett. 295, 262 (2010).

63. D. Lemarchand, ]. Gaillardet, E. Lewin, C. J. Allègre, Nature 408, 951 (2000).
64. R. M. Coggon, D. A. Teagle, C. E. Smith-Duque, ]. C. Alt, M. J. Cooper, Science 327, 1114 (2010)

65. R. E. Zeebe, A. Ridgwell, in Ocean Acidification J.-P. Gattuso, L. Hansson, Eds. (Oxford Univ. Press, Oxford, 2011), pp. 21-40.

66. S. M. Stanley, L. A. Hardie, Palaeogeogr. Palaeoclimatol. Palaeoecol. 144, 3 (1998).

67. ]. B. Ries, Biogeosciences 7, 2795 (2010).

68. C. Turley et al., Mar. Pollut. Bull. 60, 787 (2010)

69. N. Gruber, Philos. Trans. R. Soc. A-Math. Phys. Eng. Sci. 369, 1980 (2011)

70. E. T. Sundquist, K. Visser, Elsevier, in Treatise on Geochemistry: Biogeochemistry, W. H. Schlesinger Ed. (Elsevier, Pergamon, Oxford, 2004), chap. 9.

71. J. A. D. Dickson, Science 298, 1222 (2002).

72. R. V. Demicco, T. K. Lowenstein, L. A. Hardie, R. J. Spencer, Geology 33, 877 (2005).

73. A. Ridgwell, Mar. Geol. 217, 339 (2005).

Acknowledgments: Funding for the "Workshop on Paleocean Acidification and Carbon Cycle Perturbation Events" was provided by NSF OCE 10-32374 and Past Global Changes (PAGES). We thank the workshop participants for stimulating discussions and contributions to this manuscript, and the USC Wrigley Institute on Catalina Island for hosting the workshop. Particular thanks are owed to Thorsten Kiefer of PAGES, who initiated the workshop and supported it at all stages. This work is a contribution to the "European Project on Ocean Acidification" (EPOCA). Data presented in Fig. 4 are presented in tables S2 and S3 (2).

Supporting Online Material

www.sciencemag.org/cgi/content/full/335/6072/1058/DC1 SOM Text

Figs. $\mathrm{S} 1$ to $\mathrm{S3}$

Tables S1 to S3

References (74-217)

10.1126/science. 1208277 
Review: "The geological record of ocean acidification" by B. Hönisch et al. (2 March, p. 1058). The affiliation for author Carles Pelejero was incomplete. The complete affiliation is: "Institució Catalana de Recerca i Estudis Avançats and Department of Marine Biology and Oceanography, Institut de Ciències del Mar, Consejo Superior de Investigaciones Científicas, 08003 Barcelona, Catalonia, Spain." 